\title{
A STUDY OF NONSTOICHIOMETRIC OXIDES IN THE Ln-Ni-O (Ln=La, Pr, Nd) SYSTEM
}

\author{
Sergiy Nedilko ${ }^{\mathrm{a}}$, Olexander Dziazko ${ }^{\mathrm{a}}$, Vadym Kulichenko ${ }^{\mathrm{b}}$, Victoria Chornovol ${ }^{\mathrm{b}}$ \\ a Department of Chemistry, Taras Shevchenko National University of Kyiv, Volodymyrska Street, \\ 64/13, Kyiv 01601, Ukraine\} \\ ${ }^{\mathrm{b}}$ Department of Chemistry, Kyiv National University of Building and Architecture, Povitroflotsky \\ pr., 31, Kyiv 03680, Ukraine \\ contactinge-maildziazko@mail.univ.kiev.ua
}

Keywords: coprecipitation method, non-stoichiometric compositions, nickelates, rare earth oxides, $\mathrm{K}_{2} \mathrm{NiF}_{4}$.

The non-stoichiometric compositions $\mathrm{Ln}_{2-\mathrm{x}} \mathrm{NiO}_{4-3 \mathrm{x} / 2+\delta}$ ( $\left.\mathrm{Ln}=\mathrm{La}, \mathrm{Pr}, \mathrm{Nd}, 0 \leq \mathrm{x} \leq 0,4\right)$ were obtained using coprecipitation method from nitrates solutions by $\mathrm{K}_{2} \mathrm{CO}_{3}$ followed by calcination of the obtained blend at $950^{\circ} \mathrm{C}$. According to X-ray phase analysis compositions in the range $\mathrm{La}_{2} \mathrm{NiO}_{4.17}-\mathrm{La}_{1.6} \mathrm{NiO}_{3.63}$ are monophase and crystallize in tetragonal symmetry $\mathrm{K}_{2} \mathrm{NiF}_{4}$, space group I4/mmm. $\mathrm{Nd}_{2-\mathrm{x}} \mathrm{NiO}_{4-\mathrm{y}}$ and $\mathrm{Pr}_{2-\mathrm{x}} \mathrm{NiO}_{4-\mathrm{y}}$ in the range $0 \leq \mathrm{x} \leq 0,2$ are monophase and have orthorombic and monoclinic(correspodingly) distorted $\mathrm{K}_{2} \mathrm{NiF}_{4}$ structure. Samples with $0,2<\mathrm{x} \leq 0,4$ are polyphase and contain $\mathrm{Ln}_{2} \mathrm{NiO}_{4}(\mathrm{Ln}=\mathrm{Pr}, \mathrm{Nd}), \mathrm{NiO}$ and rare earth oxides. Electrical conductivity of obtained samples has semiconducting behavior and it is strongly depended to nonstoichiometric oxygen content.

\section{Introduction}

Search for new oxide compounds based on nickelates of rare-earth elements with important physico-chemical properties for the modern science and technology is a topical issue today. The mentioned above oxide compositions have potential to be used in microelectronics, catalysis and sensor technology [1-4]. Most of the rare-earth elements form only $\mathrm{RNiO}_{3}$ compositions. Lanthanum, Praseodymium and Neodymium form Ruddlesden-Popper phases
$\mathrm{Ln}_{n+1} \mathrm{Ni}_{\mathrm{n}} \mathrm{O}_{3 \mathrm{n}+1}$. It has been reported that using sol-gel method of synthesis gives an opportunity to obtain phases with Lanthanum deficiency $\mathrm{La}_{1.9} \mathrm{NiO}_{4}$ [5]. The goal of the research was synthesis of nonstoichiometric phases $\mathrm{Ln}_{2-}$ ${ }_{x} \mathrm{NiO}_{4-y}$ and studying their characteristics.

\section{Results and discussion}

The combined thermogravimetric and IRspectroscopic studies showed that the 
decomposition of the blend proceeds in the following three stages:

1 - decomposition of the hydrooxocarbonate groups, accompanied by a loss of water and $\mathrm{CO}_{2}$, at $150-160{ }^{\circ} \mathrm{C}$;

2 - decomposition of the carbonate groups, accompanied by a loss of $\mathrm{CO}_{2}$, at $450-460{ }^{\circ} \mathrm{C}$;

3 - crystallization in the $880-900{ }^{\circ} \mathrm{C}$ temperature range.

Taking into account the results of these studies, we have chosen a calcination temperature of $950^{\circ} \mathrm{C}$ for the sample synthesis. The blend was calcined during $10 \mathrm{~h}$ in alundum crucibles. The pellets were calcined during $8 \mathrm{~h}$. All the synthesized samples were black powders that could easily be dissolved in mineral acids.

According to X-ray phase analysis compositions in the range $\mathrm{La}_{2} \mathrm{NiO}_{4.17}-$ $\mathrm{La}_{1.6} \mathrm{NiO}_{3.63}$ are monophase and crystallize in tetragonal symmetry $\mathrm{K}_{2} \mathrm{NiF}_{4}$, space group I4/mmm. Crystal lattice parameters of $\mathrm{La}_{2} \mathrm{NiO}_{4.17}-\mathrm{a}=0,384(3) \mathrm{nm}$ and $\mathrm{c}=1,26(3) \mathrm{nm}$.

Samples $\mathrm{Nd}_{2-\mathrm{x}} \mathrm{NiO}_{4-\mathrm{y}}$ with $0 \leq \mathrm{x} \leq 0,2$ are monophase and have orthorombic distorted $\mathrm{K}_{2} \mathrm{NiF}_{4}$ structure. Samples with $0,2<\mathrm{x} \leq 0,4$ are polyphase and contain $\mathrm{Nd}_{2} \mathrm{NiO}_{4}$ phase, $\mathrm{NiO}$ and $\mathrm{Nd}_{2} \mathrm{O}_{3}$. Crystal lattice parameters of $\mathrm{Nd}_{2} \mathrm{NiO}_{4,20}$ are $\mathrm{a}=0,545(0) \mathrm{nm}, \mathrm{b}=0,536(8) \mathrm{nm}, \mathrm{c}=0,123(3)$ nm.

Compositions $\operatorname{Pr}_{2-\mathrm{x}} \mathrm{NiO}_{4-\mathrm{y}}$ with $0 \leq \mathrm{x} \leq 0,2$ are monophase and have monoclinic distorted $\mathrm{K}_{2} \mathrm{NiF}_{4}$ structure. Crystal lattice parameters of $\mathrm{Pr}_{2} \mathrm{NiO}_{4.20}$ are $\mathrm{a}=0.383(1) \mathrm{nm}, \mathrm{b}=0.384(1) \mathrm{nm}$ and $c=1.243(2) \mathrm{nm}, \quad \gamma=90.4(1)^{\circ}$. Similar to neodymium system samples with $0,2<x \leq 0,4$ are polyphase and contain $\mathrm{Pr}_{2} \mathrm{NiO}_{4}$, rare earth and nickel oxides.

The stabilization of non-stoichiometric nickelate phases most likely is due to ion vacancies formation. In other words we can consider formation of those phases as isomorphous substitution of rare earth ions to vacancies - $\mathrm{Ln}_{2-\mathrm{x}} \square_{\mathrm{x}} \mathrm{NiO}_{4-\mathrm{y}}$.

Electrical conductivity of obtained samples have semiconducting behavior and it is strong depended to nonstoichiometric oxygen content (Fig.1).

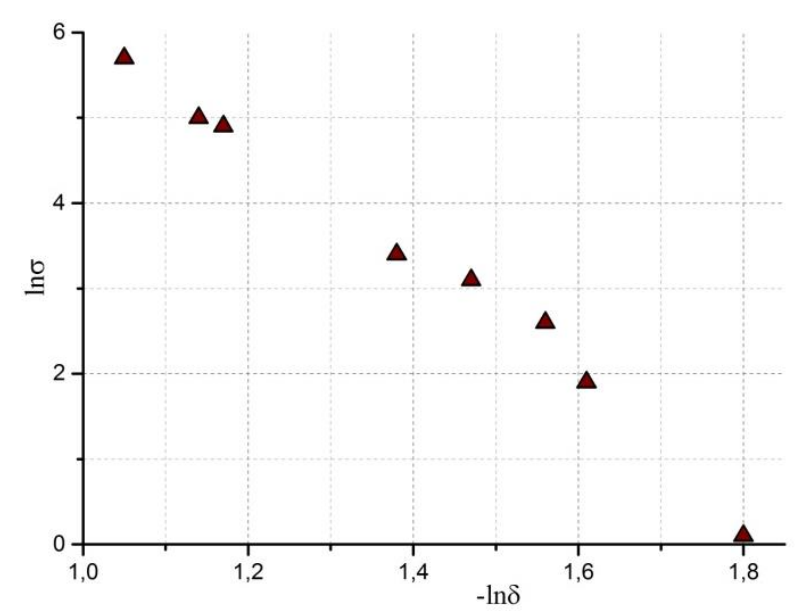

Figure 1. The dependence of conductivity on nonstoichiometric oxygen content $\delta$ in samples $\mathrm{La}_{x} \mathrm{NiO}_{1,5 \mathrm{x}+1+\delta}$ at $\mathrm{T}=293$.

\section{Conclusions}

Samples of the $\mathrm{Ln}_{2-\mathrm{x}} \mathrm{NiO}_{4-\mathrm{y}}$ ( $\mathrm{Ln}=\mathrm{La}, \mathrm{Pr}$, $\mathrm{Nd}$ ) systems were obtained using coprecipitation from aqueous solutions of rareearth metal and nickel nitrates with $\mathrm{K}_{2} \mathrm{CO}_{3}$ 
solution, followed by calcination of the blends obtained this way.

It is shown that in compositions $\mathrm{Ln}_{2-}$ ${ }_{x} \mathrm{NiO}_{4-\mathrm{y}}$ in the ranges $0 \leq x \leq 0.4(\mathrm{Ln}=\mathrm{La})$ and 0 $\leq x \leq 0.2(\mathrm{Ln}=\mathrm{Pr}$ and $\mathrm{Nd})$ nonstoichiometric compounds are obtained.

Electrical conductivity of obtained samples have semiconducting behavior and it is strong depended to nonstoichiometric oxygen content. It is can be explained by dominating role of -Ni-O- layers in the electron transport processes.

\section{Experimental part}

To prepare solutions, we used $\mathrm{La}, \mathrm{Ni}$ and Ca nitrates ("pure for analysis") as starting substances. A trilonometric analysis of the metal content in the solutions was performed according to the techniques described in [6-8]. A $0.25 \mathrm{M}$ solution of $\mathrm{K}_{2} \mathrm{CO}_{3}$ ("chemically pure") was used for the precipitation.

We studied the coprecipitation processes using a model mixture of $\mathrm{La}\left(\mathrm{NO}_{3}\right)_{3}$ and $\mathrm{Ni}\left(\mathrm{NO}_{3}\right)_{2}$ solutions. The ratio between the $\mathrm{La}^{3+}$ and $\mathrm{Ni}^{2+}$ concentrations was $\mathrm{La}^{3+}: \mathrm{Ni}^{2+}=3: 2$, for the total concentration $\left[\mathrm{La}^{3+}\right]+\left[\mathrm{Ni}^{2+}\right]=0.10 \mathrm{M}$. It was shown that a complete precipitation of metal ions with $\mathrm{K}_{2} \mathrm{CO}_{3}$ solution is achieved at a molar fraction of the sum of precipitated ions with respect to the precipitator $n=1.75$ in the range $\mathrm{pH}=10-10.2$.

To prepare the blend, the metal solutions were mixed (at the required ratios) in a beaker using a magnetic mixer. The required amount of the precipitator was quickly added to the wellstirred solution. Then the whole mixture was agitated during 1-2 h. The coprecipitated hydrooxocarbonates were held for 3 days to age the precipitate. After this, the degree of metal ion precipitation was analyzed. Then the precipitates were filtered off, washed in distilled water, a 1:1 water-acetone mixture, pure acetone and dried in air. The dried blend was exposed to thermal treatment at $900{ }^{\circ} \mathrm{C}$ for $10 \mathrm{~h}$. After this it was ground, pressed into pellets and calcined in air at $1000{ }^{\circ} \mathrm{C}$ for $8 \mathrm{~h}$. Then the blend was cooled down to room temperature in the oven.

The IR spectra taken from the pressed into pellets mixed with $\mathrm{KBr}$ ("special purity, class $3-4 ")$ in the 400-4000 $\mathrm{cm}^{-1}$ frequency range using a UR-10 instrument. Thermogravimetric studies of the coprecipitated blend were performed with a derivatograph Q-1500 produced by MOM (Hungary). We studied blend pieces of about $0.2-0.4 \mathrm{~g}$. The sample heating rate was $10^{\circ} \mathrm{C} / \mathrm{min}$. X-ray powder diffraction (XRD) studies of the samples were performed using a DRON-3 instrument $\left(\mathrm{Cu}_{K a^{-}}\right.$ radiation, Ni filter).

The excess oxygen content was determined by iodometric titration techniques [9-10]. The conductivity of the samples $(12 \times 2$ mm pellets with deposited In-Ga contacts) was measured in the 300-78 $\mathrm{K}$ temperature range using the four-probe technique with a ASTS-R 
(Automated System for Superconductors

Testing - R) plant.

\section{References}

[1] M. Hrovat, N. Katsarakis, K. Reichmann et all. Solid State Ionics. 1996, Vol. 83. № 1-2. P. 99-105.

[2] H. Zhao, Q. Li, L.P. Sun, Science China Chemistry, 2011, Volume 54, Issue 6, pp 898-910

[3] M. L. Faro, D. L. Rosa, I. Nicotera, V. Antonucci, A. S. Aricò, Applied Catalysis B: Environmental, 2009, Volume 89, Issues 1-2, 3 P. 49-57

[4] M.C. Álvarez-Galván, V.A. de la Peña O'Shea, G. Arzamendi, B. Pawelec, L.M. Gandía, J.L.G. Fierro, Applied Catalysis B: Environmental, 2009, Volume 92, Issues 3-4, P. 445-453

[5] E.Boehm, J.M. Bassat, P.Dordor et al. Solid State Ionics, 2005, v.176, 2717-2725.

[6] G. Schwarzenbach, H. Flaschka, Die komplexometrische Titration, Ferdinand Enke Verlag, Stuttgart (1965) (in German).

[7] F. Umland, A. Janssen, D. Thierig, G. Wünsch, Theorie und praktische Anwendung von Komplexbildern, Akademische Verlagsgesellschaft, Frankfurt am Main (1971) (in German).

[8] R. Přibil, Komplexony v chemické analyse, Nakladatelství Československé Akademie Věd, Prague (1953) (in Czech).

[9] G. Charlot, Les méthodes de la chimie analytique, analyse quantitative minérale, Masson et Co. (1961) (in French).

[10] V.A. Kulichenko, S.A. Nedilko, A.G. Dziazko, Visn. Kievs. Univ. Khim. 33 (1996) 130 (in Ukrainian). 